\title{
Analysis of the soiling effect on solar-panel power efficiency in the Colombian Caribbean region
}

\author{
Análisis del efecto de ensuciamiento sobre la eficiencia de paneles solares en el Caribe \\ Colombiano
}

\section{Juan David Diazgranados-Garzón (D) ${ }^{1}$, Juan Camilo Romero-Bravo (D) ${ }^{1}$, Loraine Isabel Navarro-Estrada (iD ${ }^{1 *}$, Rafael de Jesús Castillo-Sierra (D) ${ }^{1}$, José Daniel Soto-Ortiz (D) ${ }^{1}$, Mauricio Pardo-González (D) ${ }^{1}$}

${ }^{1}$ Departamento de Ingeniería Eléctrica y Electrónica, Universidad del Norte. Km.5 Antigua Vía Puerto Colombia. C. P. 081007. Atlántico, Colombia.

\section{CITE THIS ARTICLE AS:}

J. D. Diazgranados, J. C.

Romero, L. I. Navarro, R. J.

Castillo, J. D Soto and M.

Pardo. "Analysis of the

soiling effect on

solar-panel power

efficiency in the Colombian

Caribbean region", Revista

Facultad de Ingeniería

Universidad de Antioquia,

no. 97, pp. 22-29, Oct-Dec

2020. [Online]. Available:

https://www.doi.org/

10.17533/udea.redin.

20191156

\section{ARTICLE INFO:}

Received: November 20, 2018

Accepted: December 16, 2019

Available online:

December 16, 2019

\section{KEYWORDS:}

ANOVA; Particulate material characterization; power efficiency

detriment; PV

performance

Caracterización de material particulado; disminución en eficiencia de potencia; rendimiento paneles solares
ABSTRACT: This paper summarizes the impact of soil/dirt in solar-panel performance in the Colombian Caribbean Region. The corresponding experiment compares the performance of two identical solar panels, which are subjected to different scenarios. The objective of this research is, to categorize or establish on site solar-radiation ranges in order to estimate the actual solar-panel efficiency compared to $1000 \mathrm{~W} / \mathrm{m}^{2}$. The maximum power point is calculated using an $I$ vs $V$ transfer function approximation. The soiling related maximum-power-point impact analysis is carried out with a complete Multivariate Analysis of Variance (ANOVA) considering three fundamental factors: dirt/particles, solar radiation and day. According to experimental results, the soiling effect in the solar-panel efficiency reduction has been estimated as up to $6 \%$ during times of the day with the maximum solar radiation; while for lower radiations, the effect decreases exponentially becoming negligible on the available electric power. Thus, empirically it is shown that the effect of dirt/particles is significant from a clean solar-panel to one with light accumulation, but such a negative effect rapidly diminishes as accumulation changes from light to heavy. Therefore, it is suggested that once some dirt accumulates on a panel, a cleaning procedure can wait until the particle accumulation becomes heavy. Thus, this study can become a tool that solar-power-plant operators can employ to estimate the trade-off between photovoltaic-system power efficiency and its financial viability.

RESUMEN: Este artículo analiza el efecto del material particulado sobre el rendimiento de paneles solares en la Región Caribe Colombiana. Durante el experimento se compara el rendimiento de dos paneles solares identicos sometidos a diferentes escenarios. El objetivo es categorizar y establecer rangos de radiacion solar para estimar su eficiencia comparado con la de $1000 \mathrm{~W} / \mathrm{m}^{2}$. El máximo punto de potencia es calculado usando la aproximación de la curva de transferencia $I$ vs $V$, para luego analizar el impacto de la suciedad a través de un análisis de varianza multifactorial completo (ANOVA) considerando tres factores fundamentales: suciedad/partículas, radiación solar y día. Según los resultados, se estima que el efecto de la suciedad en la eficiencia decae hasta un $6 \%$ durante las horas del día con la máxima radiación solar; para radiaciones menores, el impacto en la eficiencia disminuye exponencialmente, lo que implica que la suciedad puede ser insignificante de acuerdo con la potencia disponible. Este estudio revela que el efecto de la suciedad es significativo cuando el panel pasa de limpio a ligeramente sucio, pero este efecto disminuye rápidamente cuando la acumulación cambia de ligera a pesada. Así, se sugiere que una vez el panel tenga suciedad acumulada, los procedimientos de limpieza esperen hasta que la acumulación sea pesada. Así, este estudio se convierte en una herramienta para estimar la relación entre la eficiencia energética de los sistemas fotovoltaicos y su viabilidad financiera.

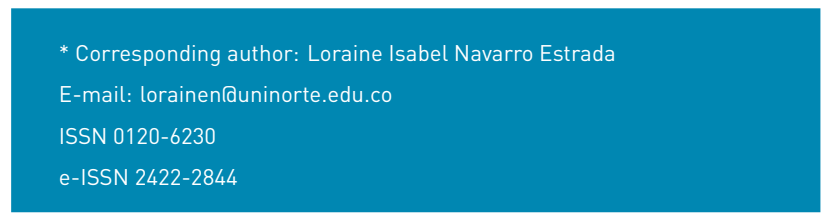




\section{Introduction}

Typically, most of the power generation systems use fossil fuels to provide a reliable energy source, but such fuel selection comes with the emission of greenhouse gases that contribute to climate change. Thus, power generation through ecofriendly renewable sources has received increased attention as a way to diversify energy options, exploit abundant resources, and reduce the carbon footprint. In this regard, one of such options that has increased rapidly is the energy generation through photovoltaic plants (PVPs). PVPs have experienced a significant drop in their development prices mainly due to the cost reductions associated to photovoltaic panels (PPs). However, since PP efficiency is still reduced (around 18\%-20\%), mitigating adverse effects is important to maximize effective electrical output and financial viability.

Along to solar radiation and module temperature, PP dirt accumulation is considered as a key detriment factor on energy-conversion efficiency because incident light over the PP surface gets reduced. Dust and other particulate accumulation on PP cause transmission loss [1]. Such accumulation referred as Soiling depends on geographical location, installation conditions and environmental factors such as temperature, humidity, wind direction and rainfall $[2,3]$. In [4], it has been demonstrated that the effect of soiling in some solar modules causes a reduction of the electrical output of around 4\%. In [5], a study with the effect of three kinds of dry particle depositions is carried out. The authors estimated the transmittance loss in PVPs for different locations. The results in [4] vary according to the study zone. Even, some research shows that the soiling can produce an efficiency degradation up to $50 \%$ in dry locations such as deserts [6]. On the other hand, soiling losses become irrelevant in rainy places because rainfalls lead to PP self-cleaning [7].

Thus, a PP cleaning protocol can turn into a complex task; mainly, if such protocol tries to adjust to the mentioned dynamic behavior. An adjustable cleaning protocol means higher costs and/or auxiliary systems that require power to operate; and therefore, can waste the expected power savings due to cleaning. Devising a proper cleaning protocol could be non-viable if time required for the process and strict environmental regulations are also considered.

Many studies have focused on the impact of dust deposition on PP output performance. Hence, some works conclude that the soiling losses have a linear behavior, and the efficiency degradation depends on dirt-particle size [8-10]. In particular, in [9] is reported that coarser dust particles have less impact on the PP power output than fine ones, and the characteristics of dust le.g., limestone, cement, carbon) have different contribution to PP efficiency deterioration. Therefore, several studies have been conducted about PP performance evaluation in different geographical locations considering dust characterization $[11,12]$. These studies attempt to obtain a correlation between different physical properties of dust li.e. size, thickness, chemical composition) and power degradation. Thus, each research can stablish different conclusions regarding the studied area. Literature has shown that evaluating PP performance can be related to short-circuit current $\left(I_{s c}\right)$ and the maximum power output $\left(P_{m}\right)[13,14]$; since soiling impact in open-circuit voltage is negligible $[13,14]$. Thus, a proper performance evaluation requires determining the $P$ vs. $V$ curve under different parameters such as radiation levels, load and dust amount. Thus, for this work, an experimental analysis starts with a Multi-Factor Analysis of Variance (ANOVA) with respect to the PP performance defined as the difference in the amount of electric power available between a test PP and a control PP (clean) for the particular conditions of the Colombian Caribbean Region. The considered factors are the Soiling, the Solar Radiation and the Day. This experiment is framed in the Photovoltaic Energy Laboratory of Universidad del Norte in Barranquilla, Colombia.

Accordingly, first, this paper presents the Design of Experiments, where the methodology is described, the factors considered are listed along to their ranges and levels, and the response variable is selected. Later, the paper explains the Experiment Statistical Analysis, where variable relationships are established, and from those define tendencies in PP performance that finally allow to state conclusions and recommendations with respect to the design and operation of PVPs in the selected location.

\section{Design of experiments}

\subsection{Characterization of dust material physical properties}

For the corresponding experiments, two identical solar panels are used where both (reference and test) were left on site for more than two weeks allowing particle material accumulation. Then, the deposited material is collected and classified using sieves for granule-size classification. The procedure for classification followed the Colombian Regulation from the INVIAS (Colombian National Roads Institute) I.N.V.E -123-07 [15]. Thus, 50g of collected dust material is classified into diameter values ranging 0.0075 $\mathrm{mm}$ to $0.85 \mathrm{~mm}$ (See Table 1).

Given the results of Table 1, an artificial dust material can be defined/selected for controlled experimentation. Thus, 
Table 1 Physical properties characterization of collected dust material

\begin{tabular}{llll}
\hline $\begin{array}{l}\text { Standard sieves } \\
\text { ASTM E - 11/95 }\end{array}$ & $\begin{array}{l}\text { Diameter } \\
\text { (mm) }\end{array}$ & Weight $(\mathbf{g})$ & $\mathbf{\%}$ \\
\hline Strainer 200 & 0.075 & 21.4 & $43 \%$ \\
Strainer 100 & 0.15 & 5.0 & $10 \%$ \\
Strainer 60 & 0.25 & 1.4 & $3 \%$ \\
Strainer 50 & 0.3 & 2.1 & $4 \%$ \\
Strainer 40 & 0.425 & 5.7 & $11 \%$ \\
Strainer 20 & 0.85 & 5.0 & $10 \%$ \\
Strainer 10 & 0.1 & 1.4 & $3 \%$ \\
Bottom & $<0.075$ & 7.0 & $16 \%$ \\
\hline Total & & $\mathbf{5 0}$ & $\mathbf{1 0 0 \%}$ \\
\hline
\end{tabular}

under a controlled setting, different density soiling levels can be defined to analyze PP behavior and get reliable results $[16,17]$. To obtain a comparable material, sand is collected out of a shore of a nearby river and then, the sieving procedure is repeated. Table 2 shows the physical properties characterization of the collected river sand. This type of material is selected because $58 \%$ of its components have a smaller diameter than $0.0075 \mathrm{~mm}$ which agrees with the natural material reported in Table 1. Comparing the data of Tables 1 and 2, both materials can be considered similar because their average difference is around $4.683 \%$, and the highest difference in their granular distribution is about $7.81 \%$. Thus, the river sand is a suitable controlled soiling material.

Table 2 Physical properties characterization of fine sand

\begin{tabular}{llll}
$\begin{array}{l}\text { Standard sieves } \\
\text { ASTM E - 11/95 }\end{array}$ & $\begin{array}{l}\text { Diameter } \\
\text { (mm) }\end{array}$ & Weight $\mathbf{( g )}$ & $\mathbf{\%}$ \\
\hline Sieve 200 & 0.075 & 177.51 & $40.23 \%$ \\
Sieve 100 & 0.15 & 37.8 & $8.57 \%$ \\
Sieve 60 & 0.25 & 35.48 & $8.042 \%$ \\
Sieve 50 & 0.3 & 44.23 & $10.03 \%$ \\
Sieve 40 & 0.425 & 84.88 & $19.24 \%$ \\
Sieve 20 & 0.85 & 10.8 & $2.45 \%$ \\
Sieve 10 & 0.1 & 0.2 & $0.045 \%$ \\
Bottom & $<0.075$ & 50.3 & $11.4 \%$ \\
\hline Total & $\mathbf{4 4 1 . 2}$ & $\mathbf{1 0 0 \%}$ \\
\hline
\end{tabular}

\subsection{Characterization of solar radiation}

This experiment is intended for dividing a day into different solar radiation categories considering their statistical characteristics. In order to identify these categories, historic data between years 2009 and 2015 are analyzed; and then, the categories are selected based on the Fisher's Least Significant Difference method (LSD). The day is divided in hour ranges considering if a statistical difference exists among those ranges. The method is based on the F-ratio to determine if the average of two similar categories is statistically equal $\left(H_{0}: y_{i}=y_{j}\right)$ or not $\left(H_{1}: y_{i} \neq y_{j}\right)$. Thus, the Equation 1 defines if hour ranges are significantly different:

$$
\left|\overline{y_{i}}-\overline{y_{j}}\right|>L S D
$$

where $\overline{y_{i}}$ and $\overline{y_{j}}$ represents means of two different populations; and LSD is defined as:

$$
L S D=t_{\alpha / 2, N-a} \sqrt{M S_{e}\left(\frac{1}{n_{i}}+\frac{1}{n_{j}}\right)},
$$

where $t_{\alpha / 2, N-a}$ value represents the critical value from the t-distribution table with a $\alpha$ confidence, $M S_{E}$ is the mean square of error, and $n$ the number of data points used to calculate the means.

Table 3 summarizes the statistically different ranges obtained from Equations 1 and 2. For instance, the range from 10:00 to $11: 59$ and that from $12: 00$ to $13: 59$ are statistically equal and the average value is around 839.71 $\mathrm{W} / \mathrm{m}^{2}$

Table 3 Hourly range with similar solar radiation

\begin{tabular}{llll}
\hline Category & Morning hour & $\begin{array}{l}\text { Afternoon/ } \\
\text { Evening hour }\end{array}$ & $\begin{array}{l}\text { Average value } \\
\text { of radiation } \\
\text { solar }\left(\mathbf{W} / \mathbf{m}^{\mathbf{2}}\right)\end{array}$ \\
\hline I & $00: 00-05: 59$ & $18: 00-23: 59$ & 0.00 \\
II & $06: 00-06: 59$ & $17: 00-17: 59$ & 64.65 \\
III & $07: 00-07: 59$ & $16: 00-16: 59$ & 216.73 \\
IV & $08: 00-08: 59$ & $15: 00-15: 59$ & 471.61 \\
V & $09: 00-09: 59$ & $14: 00-14: 59$ & 692.58 \\
VI & $10: 00-11: 59$ & $12: 00-13: 59$ & 839.71 \\
\hline
\end{tabular}

\subsection{Response variable and factors selection}

In this study, the variable response is the maximum power point (MPP) reduction of a PP. Two $210 \mathrm{~W}$ polycrystalline panels SUN ELECTRONICS Sun-A-210-fa3c are employed, where one is used as a reference (clean panel) and the other one is evaluated under different dust accumulation [18]. With these measurements, it is possible to estimate the response-variable behavior in a PP controlled environment. Both PPs are classified as Grade $A$; that is, the modules do not have any visible defect nor present measurable electrical issues under test. The modules are placed in a custom-made base (see Figure 1) with $11^{\circ}$ tilting and oriented towards south due to the geographic position of the city (LAT $11.0^{\circ} \mathrm{N}$, LONG $74.8^{\circ} \mathrm{O}$, Barranquilla, Colombia).

Given that the PP area equals $1.572 \mathrm{~m}^{2}$, the modules have nominal efficiency close to $13.4 \%$ at $1,000 \mathrm{~W} / \mathrm{m}^{2}$. 
However, considering the estimated average found for Solar Radiation Category VI in Table $3\left(839.71 \mathrm{~W} / \mathrm{m}^{2}\right)$, the highest average efficiency is in fact around $11.2 \%$. This value is an estimation considering the total area of the solar panel and the real power obtained from it, given the estimated maximum solar radiation compared to the STC $1,000 \mathrm{~W} / \mathrm{m}^{2}$. Note that the employed radiation for efficiency calculation comes from the estimated average found for Solar Radiation Category VI which can include cloudy conditions that lowers the STC metric. Since the efficiency estimation is empirical, aspects such as cell temperature are already embedded in the calculation. It is important to notice that since efficiency requires estimating the MPP, such estimation must be carried out from an approximation of the complete $I$ vs. $V$ transfer function using MATLAB, since PP characterization is done with limited number of points.

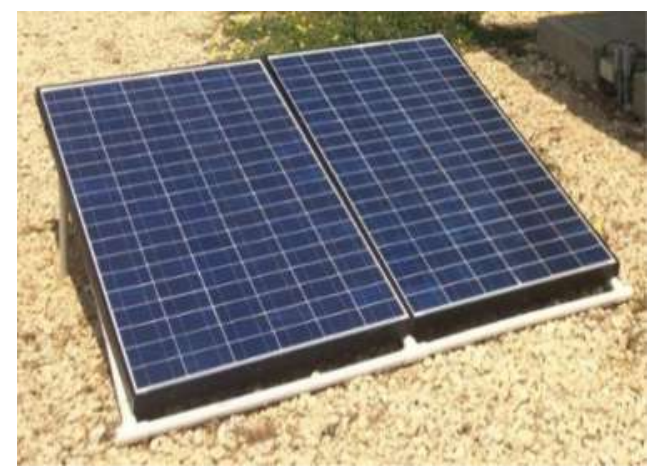

Figure 1 Installation setup for the PPs with $11^{\circ}$ tilting orientation south

The factors considered for this experiment are Soiling, Solar Radiation and Day. Soiling is a quantitative variable classified by dust accumulation (weight) per square meter on the PP $\left(\mathrm{g} / \mathrm{m}^{2}\right)$. In literature [16], four levels of soiling are listed as Clean $\left(0 \mathrm{~g} / \mathrm{m}^{2}\right)$, Light $\left(10 \mathrm{~g} / \mathrm{m}^{2}\right)$, Moderate $\left(20 \mathrm{~g} / \mathrm{m}^{2}\right)$, and Heavy $\left(30 \mathrm{~g} / \mathrm{m}^{2}\right)$. Thus, the amount of deposited artificial dust can be calculated considering the PP area $\left(1.572 \mathrm{~m}^{2}\right)$.

As mentioned previously, for the Solar Radiation, there are six discrete categories, which are statistically different. However, the first category (CAT I: $0 \mathrm{~W} / \mathrm{m}^{2}$ ) can be ignored due to its null value (see Table 3). For this study, the Day is considered as another factor, so that environmental variations can be identified during the experiment. Since each measurement is taken for both PPs (clean and under test) simultaneously, unexpected variations can be identified and eliminated for the conclusions. Finally, different values of electric loads are used to evaluate different points of the $I$ vs. $V$ curve to cover the MPP of the two PPs during the test.

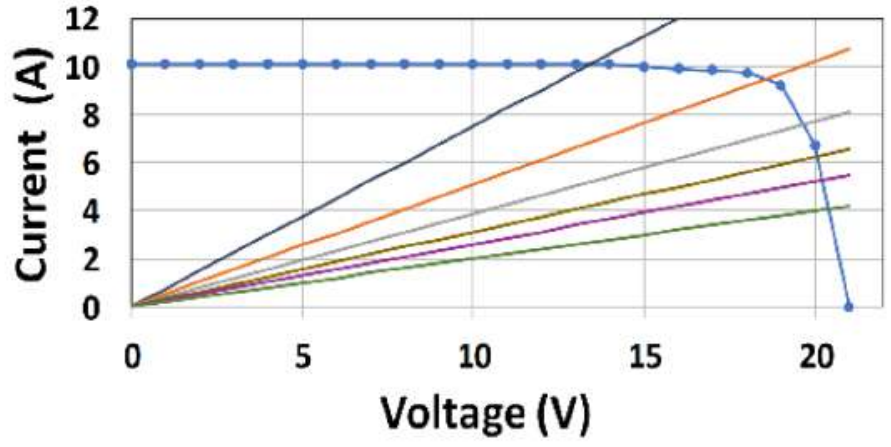

$\rightarrow 1-\operatorname{LOAD} 1-\operatorname{LOAD} 2-\operatorname{LOAD} 3-\operatorname{LOAD} 4-\operatorname{LOAD} 5-$ LOAD 6

(a)

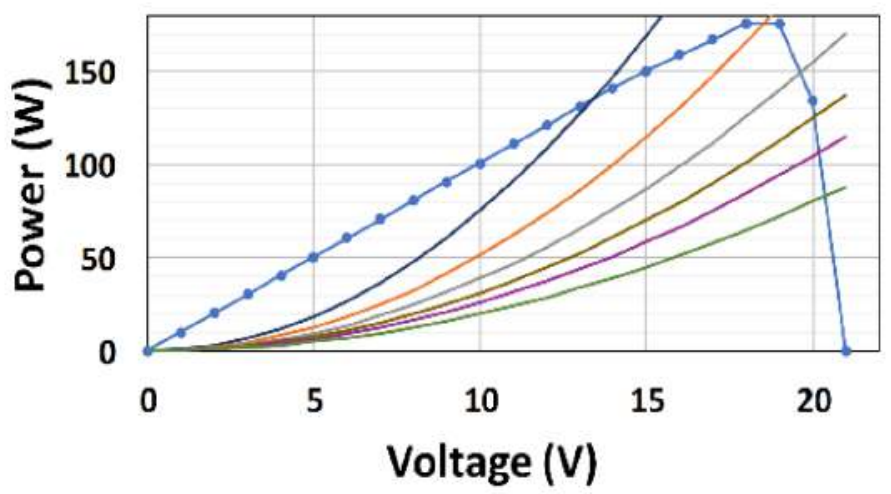

$\because 1-\operatorname{LOAD} 1-\operatorname{LOAD} 2-\operatorname{LOAD} 3-\operatorname{LOAD} 4-\operatorname{LOAD} 5-\operatorname{LOAD} 6$

(b)

Figure $2 I$ vs. $V$ (a) and $P$ vs. $V$ (b) characteristics of the PP for solar radiation Category VI along to the used load lines

The electric load values are provided by a custom-made resistor bank with six discrete resistors whose values range between $1.33 \Omega$ and $5.00 \Omega$. Figure 2 shows how the PP characterization for the Solar Radiation Category VI is achieved with the different load lines.

\subsection{Experimental design selection and output power performance}

The design of experiments is based on a complete Multi-Factor ANOVA, which considers all the possible combinations among the factor levels. Thus, the complete experiment has 220 combinations /considering four levels of Soiling, five levels of Solar Radiation, and eleven levels of Dayl. The experiment is carried out during 11 days, from March 29, 2016 to April 9, 2016 lexcept Sunday, April 3). In this case, only one repetition is taken for each level combination; therefore, a total of 220 data points are gathered.

The data collected consists basically in voltage and current measurements from both clear and "dirty" PPs 
Table 4 Variance analysis for panel performance

\begin{tabular}{llllll}
\hline Factor & Sum of the squares & Gl & Squared mean & F-ratio & P-value \\
\hline Main effects & & \multicolumn{5}{l}{} \\
\hline A: Day & 0.496 & 10 & 0.049 & 9.43 & 0.00 \\
B: Radiation & 0.263 & 4 & 0.065 & 12.52 & 0.00 \\
C: Soiling & 0.704 & 3 & 0.234 & 44.63 & 0.00 \\
\hline Interactions & & & & & \\
\hline AB & 0.833 & 40 & 0.020 & 3.96 & 0.00 \\
AC & 0.245 & 30 & 0.008 & 1.56 & 0.00 \\
BC & 0.261 & 12 & 0.021 & 4.15 & 0.00 \\
RESIDUES & 0.631 & 120 & 0.005 & & \\
\hline Total & $\mathbf{3 . 4 3 5}$ & $\mathbf{2 1 9}$ & & \\
\hline 'All F- ratios are based on the residual mean squared error
\end{tabular}

for the different levels of the experiment. With the measurements, the MPP can be estimated for each panel; and thus, the MPP variation between both panels can be determined. For the present work, the variation is defined as

$$
\frac{P_{\max 1}-P_{\max 2}}{P_{\max 2}},
$$

where $P_{\max 1}$ and $P_{\max 2}$ represent the estimated MPP of the dirty panel and the clear panel, respectively.

The procedure consists initially in taking data from both panels initially clean. Then, different amounts of artificial dust are deposited on one of the PPs using a $0.01 \mathrm{~g}$ precision weight scale; and finally, the experiment is executed for different solar radiations for the 11 days considered.

\section{Statistical analysis of the experiments}

\subsection{Relevance of the factors in panel performance}

After gathering the 220 data points, the data is processed via Statgraphics Centurion XVII version 17.0.16 software. Table 4 summarizes the results from the Multi-factor ANOVA. If the ANOVA shows the validity of the null hypothesis, $H 0: \mu_{1}=\mu_{2}=\mu_{3}=\ldots=\mu_{n}$ for each factor and interaction, lindicating that the averages of each factor level are equal to each other); then, a change in the factor does not affect the output variable significantly, that is the MPP. On the other hand, if the alternate hypothesis, $H 1: \mu_{i} \neq \mu_{j}$, is satisfied for each factor and interaction (indicating that at least a pair of averages is different); then, the considered factor does have an influence on the output variable.

Table 4 shows the variance analysis result, where the response variable is the MPP change for a PP under different amounts of soiling and radiations. Table 4 shows that for all the factors considered (Solar Radiation, Soiling and Day), the $P$-Value is less than alpha (which for this work equals 0.05 , probability of committing an error of the first kind); therefore, it can be stated that each of the factors in the experiment has a significant impact on the PP MPP. Regarding the factor Day, its effect in the experiments is relevant; therefore, data redundancy will help to foresee PP performance due to not considered factors, avoiding to draw incorrect conclusions. Since the experiments are not conducted in a $100 \%$ controlled environment, the temperature effect in the PPs would be immersed within the environmental conditions embedded in the factor Day. Regarding the factor interaction, it can be observed that all of order 2 interactions $(A B, A C, B C)$ are relevant in panel performance.

Table 5 presents a multiple comparison among all the levels of each factor. With the LSD test, it is possible to estimate which levels of Solar Radiation and Soiling are statistically different. The last column is represented by a " $\mathrm{X}$ " for each level. If at least two of the " $\mathrm{X}$ " are aligned, it can be said that those levels are statistically equal. For the case of Soiling, the LSD test shows that all its levels are different. Thus, considering their MPP averages values, it can be concluded that the MPP is reduced as the solar panel gets dirtier.

The reported average in Table 5 also includes all the levels of factor Day. Hence, the response variable average for the factor Solar Radiation is evaluated. The data reported in Table 5 allow highlighting that the average value of MPP reduction of the two panels clean (under test and reference) is $2.2 \%$. This value indicates that there exists an intrinsic error between the two modules used during testing. According to Figure 1, the modules are next to each other; therefore, the authors conclude that factors such as unintentional shading or temperature are not causing the difference but tolerances of the PPs. 
In addition, it is important to notice that Table 5 can be influenced by a scale problem. Thus, for example, a $12.13 \%$ variation reduction in MPP at the lowest Solar Radiation is still insignificant compared to "only" $1.5 \%$ at the highest Solar Radiation, which corresponds to the case when the output power is maximum.

Table 5 Average for each factor level and LSD test result

\begin{tabular}{lcccccc}
\hline Factor & Level & Average & & LSD Test & \\
\hline & 64.65 & $-12.13 \%$ & $\mathrm{X}$ & & & \\
Solar Radiation & 216.73 & $-7.4 \%$ & & $\mathrm{X}$ & & \\
$\left(\mathrm{W} / \mathrm{m}^{2}\right)$ & 471.61 & $-6.1 \%$ & & & $\mathrm{X}$ & \\
& 692.58 & $-5.6 \%$ & & $\mathrm{X}$ & & \\
& 839.71 & $-1.5 \%$ & & & & $\mathrm{X}$ \\
\hline & 0 & $2.2 \%$ & $\mathrm{X}$ & & & \\
Soiling $\left(\mathrm{g} / \mathrm{m}^{2}\right)$ & 10 & $-5.7 \%$ & & $\mathrm{X}$ & & \\
& 20 & $-9.3 \%$ & & & $\mathrm{X}$ & \\
& 30 & $-12.5 \%$ & & & & $\mathrm{X}$ \\
\hline
\end{tabular}

Then, a tendency or fitting is developed from the taken measurements during different days with the objective to focus on the Radiation-Soiling interaction. Once the fitting has been done, a new table is generated to summarize the effect of the Radiation-Soiling (BC) interaction focusing on the maximum output power. Thus, Table 6 summarizes the panel-performance average values of the defined levels of Soiling for a given fitting of the factor Radiation. In addition, Table 6 reports the Range (in W) that estimates the detriment of the output power per Radiation level. It is important to note that Range has been estimated from the power average obtained from the fitting. Table 6 also shows the difference between the MPP of the clean and dirty PPs. It can be observed that the dirt only reduces the output power in less than $6 \mathrm{~W}(2.85 \%)$ for solar radiations below $700 \mathrm{~W} / \mathrm{m}^{2}$ turning the soiling effect insignificant. The column of CONTR. (i.e. Contribution) shows that the effect of dirt/particles is significant from a clean solar panel to one with light accumulation, but rapidly diminishes as accumulation changes from light to heavy.

In particular, the column Range is plotted in Figure 3 and reveals that it follows an exponential relationship. The fiiting procedure is carried out using Statgraphics Centurion XVII version 17.0.16 software. Hence, the dirt identified in the geographical area of study only affects the output power relevantly during the times of the day close to Noon, and the detriment estimate is about $12.4 \mathrm{~W}$ or $5.9 \%$ considering the PP of the present work.

Now, since the Table 6 uses the maximum average solar radiation (around $800 \mathrm{~W} / \mathrm{m}^{2}$ ), value that differs from the STC $1000 \mathrm{~W} / \mathrm{m}^{2}$ as commented previously, the found exponential function can be employed to estimate what the maximum detriment could be considering specific values for solar radiation; such as $1000 \mathrm{~W} / \mathrm{m}^{2}$, value that
Table 6 Performance average per radiation factor levels and soiling contributions

\begin{tabular}{|c|c|c|c|c|c|}
\hline & Radiation & Soiling & $\mathbf{P}_{\max }$ & Range(W) & CONTR. \\
\hline \multirow{4}{*}{6} & \multirow{4}{*}{839.71} & 0 & 176.34 & \multirow{4}{*}{12.32} & $0.00 \%$ \\
\hline & & 10 & 169.74 & & $53.57 \%$ \\
\hline & & 20 & 165.94 & & $84.42 \%$ \\
\hline & & 30 & 164.02 & & $100.00 \%$ \\
\hline \multirow{4}{*}{5} & \multirow{4}{*}{692.58} & 0 & 145.44 & \multirow{4}{*}{5.78} & $0.00 \%$ \\
\hline & & 10 & 142.59 & & $49.31 \%$ \\
\hline & & 20 & 140.69 & & $82.18 \%$ \\
\hline & & 30 & 139.66 & & $100.00 \%$ \\
\hline \multirow{4}{*}{4} & \multirow{4}{*}{471.61} & 0 & 99.039 & \multirow{4}{*}{3.41} & $0.00 \%$ \\
\hline & & 10 & 97.809 & & $36.07 \%$ \\
\hline & & 20 & 95.629 & & $100.00 \%$ \\
\hline & & 30 & 97.839 & & $35.19 \%$ \\
\hline \multirow{4}{*}{3} & \multirow{4}{*}{216.73} & 0 & 42.80 & \multirow{4}{*}{2.71} & $100.00 \%$ \\
\hline & & 10 & 44.52 & & $36.53 \%$ \\
\hline & & 20 & 45.51 & & $0.00 \%$ \\
\hline & & 30 & 44.07 & & $53.14 \%$ \\
\hline \multirow{4}{*}{2} & \multirow{4}{*}{64.65} & 0 & 12.67 & \multirow{4}{*}{0.91} & $100.00 \%$ \\
\hline & & 10 & 13.03 & & $60.26 \%$ \\
\hline & & 20 & 13.58 & & $0.00 \%$ \\
\hline & & 30 & 13.21 & & $40.50 \%$ \\
\hline
\end{tabular}

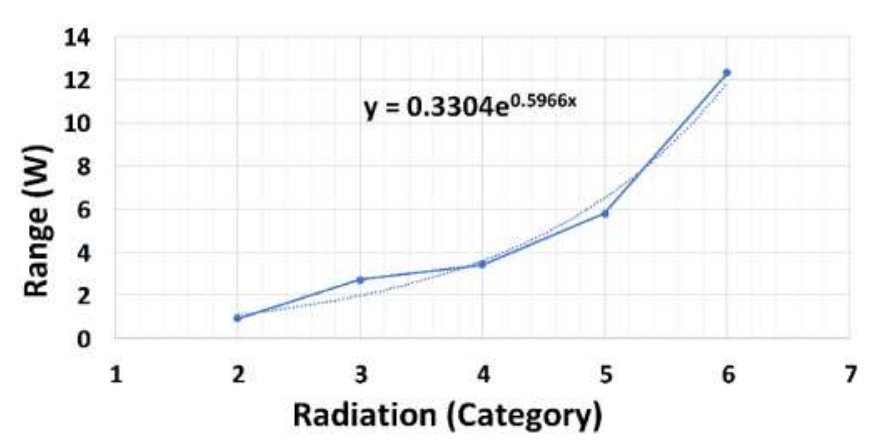

Figure 3 Exponential relationship between the detriment in output power and solar radiation categories given the soling levels for the study area

can be registered in the target location, which is close to the Equator. Higher radiation values than the average defining Category 6 expect to be more affected by soiling. Thus, a maximum reduction in the output power of around $20.5 \mathrm{~W} 09.8 \%$ is expected at the STC $1000 \mathrm{~W} / \mathrm{m}^{2}$ given the soiling levels for the city of Barranquilla (Colombia).

The estimated average maximum detriment is important when a PVP is designed with an inverter that limits the available electrical power. In some cases, the designer can deliberately reduce the electric power output fixing the inverter power lower than the maximum available power from the solar panels. Although, this design criterion may appear contrary because it does not maximize the power of the PP; in fact, it could be advantageous for 
example in terms of trade-off between the inverter cost vs. available time with maximum power (from radiation). Now, this trade-off can now be complemented considering the soiling effect, since the maximum detriment is expected when solar radiation is higher. Thus, in terms of investment and operation costs, selecting an inverter power lower than the peak power from the solar-panel field can be attractive in terms of the return of investment. For instance, the Photovoltaic Energy Laboratory at Universidad del Norte counts with 16 solar modules (similar to the one use for the study) that connect to a grid-tie inverter with a maximum output power of $3 \mathrm{~kW}$. Even though, the photovoltaic field would be able to generate up to $3.36 \mathrm{~kW}_{\text {peak }}$, but due to the inverter limiting the power to $3 \mathrm{~kW}$, the effective maximum PVP electric power is being reduced in $10.7 \%$ by design leconomic considerations), which implies that the soiling effect becomes irrelevant during the times of the day when the dirt effect is more significant.

As mentioned previously, Table 5 shows that the dirt has a significant effect, and a tendency can be derived for Radiation Categories 5 and 6 (column CONTR.); while in the other categories, the average of the experiments does not have a defined tendency, which for the authors can be an indication that the soiling effect becomes immersed in the stochastic nature of the factor Radiation. Thus, as an example, for Radiation Category 6, the soiling effect can be adjusted with an Order 3 polynomial as shown in Figure 4. Even though, the authors do not have other categories with data to fully demonstrate this tendency, the one presented empirically shows that the soiling effect is more intense starting from a clean PP to a one with light accumulation, but such effect is assuaged, in terms of cleaning, so the PVP operator can wait until the PPs presents a heavy accumulation instead of a moderate dirt.

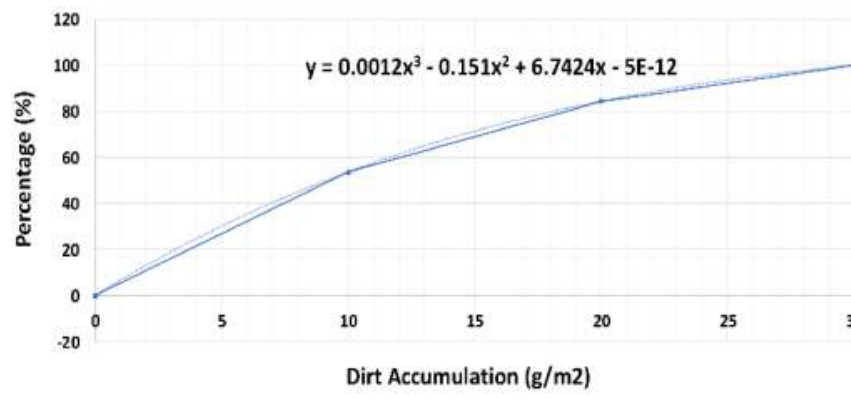

Figure 4 Polynomial fitting for the output power due to the soiling levels for Solar Radiation Category 6

\section{Conclusions}

This work presents the impact of the so-called soiling effect in panel performance in the geographical area containing the city of Barranquilla, Colombia. The used methodology for experimentation has been structured considering the environmental conditions of the area and the available resources. This work offers a simple alternative for soiling analysis without sacrificing the quality of the results. Focusing on the particular geographical area is important because there exists the objective of spreading solar photovoltaic generation in the Colombian Caribbean Region; and therefore, this work becomes a tool for the strategic operation of the PVPs. First, this work analyzes the typical dirt finding the average dimensions of the particle material that will accumulate over PPs. Then, the soiling effect has been classified into three categories: Light, Moderate and Heavy. This kind of dirt impacts the electrical PP performance that are not necessarily obtained from worldwide-approach studies.

Then, the present analysis focuses on categorizing the available solar radiation finding that the results agree with the ones reported by other studies and agencies worldwide which locate the energy potential of the geographical area to about 6 PSH (peak-sun-hours) for the city of Barranquilla, Colombia. Hence, the maximum average radiation is around $800 \mathrm{~W} / \mathrm{m}^{2}$; and for this level, the observed adverse effects due to soiling are not that detrimental if compared to higher radiation levels. For the present work, the average maximum reduction for dirt accumulation has been estimated to about $6 \%$ between 10:00 and 14:00. However, for other daytimes, the soiling effect reduces exponentially and the efficiency reduction is more due to the stochastic nature of the environmental conditions. In fact, the maximum reduction can be negligible if a PVP is designed with inverters that limit the electrical power to mitigate radiation fluctuations due to the environment or to improve financial viability. Thus, this work allows to conclude that the soiling effect can be included as "environmental radiation fluctuation"; or on the contrary, it can set the inverter power setting so that the maintenance due to cleaning can be extended. Of course, this last consideration is directly related to the typical dirt of the geographical area. In this case, the authors can suggest installing sensors that report actual dirt accumulations maximizing the time lapse between cleaning procedures.

\section{Declaration of competing interest}

None declared under financial, professional and personal competing interests.

\section{Acknowledgement}

The authors thank Universidad del Norte for the support given for this work through the Energy Strategic 
Area program, for the availability of the Photovoltaic Energy Laboratory of the Electrical and Electronics Engineering Department, and the support given for the Civil Engineering Department Labs for dirt material classification.

\section{References}

[1] A. Sayyah, M. N. Horestein, and M. K. Mazumder, "Energy yield loss caused by dust deposition on photovoltaic panels," Solar Energy, vol. 107, September 2014. [Online]. Available: https: //doi.org/10.1016/j.solener.2014.05.030

[2] M. R. Maghami and et al, "Power loss due to soiling on solar panel: A review," Renew. and Sustainable Energy Rev., vol. 59, June 2016. [Online]. Available: https://doi.org/10.1016/j.rser.2016.01.044

[3] L. Boyle, H. Flinchpaugh, and M. Hannigan, "Impact of natural soiling on the transmission of PV cover plates," in $39^{\text {th }}$ Photovoltaic Specialists Conference (PVSC), Tampa, FL, USA, 2013, pp. 3276-3278.

[4] M. Vivar and et al, "Effect of soiling in CPV systems," Solar Energy, vol. 84, no. 7, July 2010. [Online]. Available: https: //doi.org/10.1016/j.solener.2010.03.031

[5] L. Zhou and et al, "The impact of air pollutant deposition on solar energy system efficiency: An approach to estimate PV soiling effects with the community multiscale air quality (CMAQ) model," Science of the Total Environment, vol. 651, February 15 2019. [Online]. Available: https://doi.org/10.1016/j.scitotenv.2018.09.194

[6] J. J. John, S. Warade, A. Kumar, and A. Kottantharayil, "Evaluation and prediction of soiling loss on PV modules with artificially deposited dust," in $42^{\text {nd }}$ Photovoltaic Specialist Conference (PVSC), New Orleans, LA, USA, 2015, pp. 1-3.

[7] M. Naeem and G. TamizhMani, "Cleaning frequency optimization for soiled photovoltaic modules," in $42^{\text {nd }}$ Photovoltaic Specialist Conference (PVSC), New Orleans, LA, USA, 2015, pp. 1-5.

[8] R. Appels and et al, "Effect of soiling on photovoltaic modules," Solar Energy, vol. 96, October 2013. [Online]. Available: https: //doi.org/10.1016/j.solener.2013.07.017

[9] M. Mani and R. Pillai, "Impact of dust on solar photovoltaic (PV) performance: Research status, challenges and recommendations," Renew. and Sustainable Energy Rev., vol. 14, no. 9, December 2010. [Online]. Available: https://doi.org/10.1016/j.rser.2010.07.065

[10] P. D. Burton and B. H. King, "Application and characterization of an artificial grime for photovoltaic soiling studies," IEEE J. Photovolt., vol. 4, no. 1, January 2014. [Online]. Available: https://doi.org/10.1109/JPHOTOV.2013.2270343

[11] J. W. Zapata, M. A. Perez, and S. Kouro, “Design of a cleaning program for a PV plant based on the analysis of short-term and long-term effects," in $41^{\text {st }}$ Annual Conference of the IEEE Industrial Electronics Society, Yokohama, Japan, 2015, pp. 1301-1306.

[12] W. Herrmann, M. Schweiger, G. Tamizhmani, B. Shisler, and C. S. Kamalaksha, "Soiling and self-cleaning of PV modules under the weather conditions of two locations in Arizona and South-East India," in $42^{\text {nd }}$ Photovoltaic Specialist Conference (PVSC), New Orleans, LA, USA, 2015, pp. 1-5.

[13] J. J. John, S. Tatapudi, and G. Tamizhmani, "Influence of soiling layer on quantum efficiency and spectral reflectance on crystalline silicon PV modules," in 40 th IEEE Photovoltaic Specialist Conference (PVSC), Denver, CO, USA, 2014, pp. 2595-2599.

[14] A. Alshehri and et al, "Dust mitigation in the desert: Cleaning mechanisms for solar panels in arid regions," in Saudi Arabia Smart Grid Conference (SASG), Jeddah, Saudi Arabia, 2014, pp. 1-6.

[15] Manual de Normas de Ensayo de Materiales para Carreteras, Instituto Nacional de Vias, Bogotá, Colombia.

[16] J. J. John, S. Warade, G. Tamizhmani, and A. Kottantharayil, "Study of soiling loss on photovoltaic modules with artificially deposited dust of different gravimetric densities and compositions collected from different locations in india," IEEE J. Photovolt., vol. 6, no. 1, January 2016. [Online]. Available: https://doi.org/10.1109/ JPHOTOV.2015.2495208

[17] S. Boppana, V. Rajasekar, and G. TamizhMani, "Working towards the development of a standardized artificial soiling method," in $42^{\text {nd }}$ IEEE Photovoltaic Specialist Conference (PVSC), New Orleans, LA, USA, 2015, pp. 1-6.

[18] M. Gostein, T. Düster, and C. Thuman, "Accurately measuring PV soiling losses with soiling station employing module power measurements," in $42^{\text {nd }}$ IEEE Photovoltaic Specialist Conference (PVSC), New Orleans, LA, USA, 2015, pp. 1-4. 